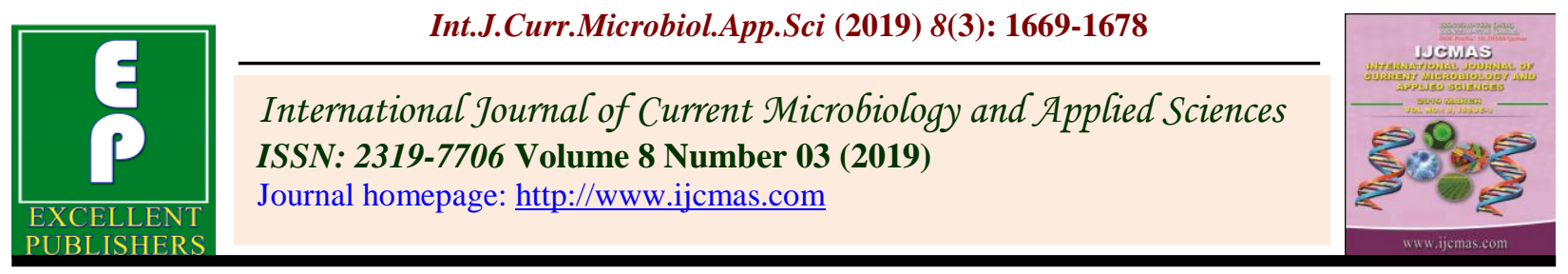

Original Research Article

https://doi.org/10.20546/ijcmas.2019.803.194

\title{
Genetic Analysis of Egg Production and Allied Characters in Two Long Term Selected Strains of White Leghorn
}

\author{
R.R. Churchil*, Lijo John, Binoj Chacko, P. Ezhil Praveena and P. Anitha \\ All India Co-ordinated Research Project on Poultry, Kerala Veterinary and Animal Sciences \\ University, Mannuthy, Thrissur-680 651, Kerala, India \\ *Corresponding author
}

\begin{tabular}{|l|}
\hline Ke y w or d s \\
$\begin{array}{l}\text { Egg Production, } \\
\text { Genetic Parameters, } \\
\text { White Leghorn }\end{array}$ \\
\hline Article Info \\
\hline $\begin{array}{l}\text { Accepted: } \\
\text { 12 February } 2019 \\
\text { Available Online: } \\
\text { 10 March 2019 }\end{array}$ \\
\hline
\end{tabular}

\section{A B S T R A C T}

The genetic parameters like population mean and genetic and phenotypic correlations were analyzed from IWN and IWP strains of White Leghorn, which were selectively bred for egg production for 23 generations. The traits analyzed were hen housed egg number up to 40 (EN40) and 64 (EN64) weeks of age, age at first egg (AFE), body weights at 16 (BW16), 40 (BW40) and 64 (BW64) weeks of age and egg weights at 28 (EW28), 40 (EW40) and 64 (EN64) weeks of age in $23^{\text {rd }}$ selected generation (S23). The mean values for different traits in IWN and IWP strains respectively were 110.67 and 105.64 eggs for EN40, 248.27 and 234.46 eggs for EN64, 154.24 and 152.65 days for AFE, 1064.48 and $1024.67 \mathrm{~g}$ for BW16, 1560.47 and $1587.34 \mathrm{~g}$ for BW40, 1547.13 and $1628.28 \mathrm{~g}$ for BW64, 51.12 and 50.37g for EW28, 54.54 and 55.04g for EW40 and 59.46 and $60.38 \mathrm{~g}$ for EW64. Moderate to high heritability estimates were recorded for EN40 (0.284), EN64 (0.182), AFE (0.349), BW16 (0.488), BW40 (0.388), BW64 (0.284), EW28 (0.375) EW40 (0.447) and EW64 (0.390) in IWN strain. Barring AFE which exhibited low magnitude (0.090), other traits like EN40 (0.239), EN64 (0.220), BW16 (0.318), BW40 (0.285), BW64 (0.242), EW28 (0.460) EW40 (0.491) and EW64 (0.505) showed moderate to high magnitude of heritability in IWP strain. Estimated genetic correlations of EN64, the primary trait of selection with other related traits viz., EN40, AFE, BW16, BW40, BW64, EW28, EW40 and EW64 were 0.824, -0.497, $-0.234,-0.070,-0.094,-0.293,-0.455$ and 0.274 respectively for IWN strain and the corresponding figures for IWP strain were $0.944,-0.516,-0.030,-0.061,-0.092,0.006,-0.073$ and 0.0 . From the heritability estimates for egg number it can be conclude that the good amount of additive genetic variance for egg production can exist in White Leghorn populations undergoing selection for long period for more than 20 generations.

\section{Introduction}

The genetic parameters of a population are required not only for predictions of responses, but also used as a base for the future selection and breeding strategies. In poultry breeding programmes, selection plays major role for the improvement of egg production performances of the flock. Pureline selection is the most commonly employed breeding technique for the production of commercial layers (Cole and Hutt, 1973). Dryden (1921) 
was among the first workers to demonstrate substantial improvement in egg production due to selection, selecting females on their own individual records and males on the performance of their dams. Selection for partor whole-record egg number or laying rate is a usual approach for improving egg production, which has been shown to yield positive genetic progress, as reviewed by Fairfull and Gowe (1990).

Selection greatly alters the properties of a population. The heritabilities and the genetic correlations are expected to change in a population after selection (Falconer, 1989). These estimates from selected strains are generally lower than those from unselected strains.

Results of long term studies can provide valuable information for scientific community and commercial breeders as well. Although there is considerable literature on genetic parameters of various economic traits in White Leghorn for a specific short or medium period or pooled over few generations of study (Johari et al., 1988; Chaudhary et al., 1996; Sharma et al., 1996), there is, a dearth of information on genetic estimates from populations which were undergone selection for a long period. Moreover, heritability estimates for part-period egg production upto 40 weeks of age is commonly reported but one calculated for full-record egg production is scarce.

Therefore the aim of the present study was to estimate heritability and genetic correlations from IWN and IWP strains of single comb White Leghorn populations selectively bred for full record egg production by pure line selection using Osborne's index (Osborne, 1957b) for more than three decades since 1975 at All India Co-ordinated Research Project on Poultry, Mannuthy, Thrissur, Kerala, India.

\section{Materials and Methods}

\section{Genetic stock and data}

The hatching eggs of base populations of IWN and IWP strains of White Leghorn were supplied by the Indian Council of Agricultural Research in the year 1978. These populations were selectively bred for egg production based on part-record egg production up to 40 weeks until $16^{\text {th }}$ generation. The testing period was then enhanced upto 60 weeks $\left(17^{\text {th }}\right.$ generation) to 64 weeks $\left(18^{\text {th }}\right.$ through $23^{\text {rd }}$ generation). Intra-population combined selection using an index (Osborne, 1957a, b) was practiced. Pressure for egg weight was included in the selection programme from third generation as an independent culling level. Initially these populations were reproduced utilizing 40 sires and 240 dams (1:6) until $13^{\text {th }}$ generation. The sire and dam bases were then modified to 50 and 400 respectively $(1: 8)$ in $14^{\text {th }}$ generation, then to 50 and $300(1: 6)$ in $15^{\text {th }}$ through $23^{\text {rd }}$ generation. In order to keep inbreeding low, full-sib and half-sib matings were avoided. A random bred control population was maintained along with the selected populations.

The summary of selection records of parent generation is given in Table 1. Fifty sires and 300 dams were used to produce S23 generation. All the sires but only 298 dams of IWN and 296 dams of IWP contributed the new generation. The selection intensity in producing new generation was 0.496 and 0.358 respectively in IWN and IWP respectively. The data was obtained from 2000 and 2014 pedigreed hens of IWN and IWP strains respectively, spread in four hatches taken at ten days interval. The hens were housed at the start of $17^{\text {th }}$ week, distributed randomly in double-deck individual Californian cages and maintained till to the end of the study to facilitate individual data collection. 


\section{Traits studied}

The following traits were measured from these populations:

1) Hen housed egg production (HHEP) up to 40 (EN40) and 64 (EN64) weeks of age was recorded on individual basis as cumulative numbers.

2) Age at First Egg (AFE) was recorded as the age of the pullet in days when she laid her first egg.

3) Mature (BW16), adult (BW40) and final (BW64) body weights were recorded individually at 16, 40 and 64 weeks of age respectively to the nearest $5 \mathrm{~g}$.

4) Egg weight at 28 (EW28), 40 (EW40) and 64 (EW64) weeks, and of age obtained as mean egg weight of four consecutive eggs recorded to the accuracy of one tenth of a gram.

\section{Genetic Analysis}

The data was corrected for hatch effect using least square analysis of variance by fitting least square constants within strain as per Harvey (1966). Using the hatch-corrected data, the heritability, phenotypic and genetic correlations were estimated as per Falconer (1989). The significance of mean difference between the strains was determined by Student's t-test (Snedecor and Cochran, 1989).

\section{Results and Discussion}

\section{Descriptive statistics of traits}

The frequency distribution of EN64, primary trait of this selection experiment revealed a high frequency of 0.35 of IWN and 0.34 of IWP observations falling in the class interval of 241 to 260 eggs (Fig. 1).

The mean values, their standard deviations and minimum and maximum values of different traits are given in Table 2. The hatch effect was significant for all the traits except EN40 and AFE in both the populations. Significant $\quad(\mathrm{P} \leq 0.001) \quad$ difference was observed for mean values of all the traits between IWP and IWN strains. IWN strain had significantly $(\mathrm{P}<0.001)$ higher $\mathrm{EN} 40$ (110.67 Vs 105.64) and EN64 (248.27 Vs 234.46), even though it matured later compared to IWP (154.24 Vs152.65d). Similar values for $40^{\text {th }}$ (Devi and Reddy, 2005; Joshi et al., 2005) and 64 ${ }^{\text {th }}$ (Devi and Reddy, 2005) week egg production in White Leghorn populations have been reported earlier. Singh et al., (2009) has reported strain difference for egg production in White Leghorn similar to the findings of the present study. The average AFE reported in White Leghorn breed was much higher in earlier reports ranging from 150 to 193.21 (Ahlawat et al., 1982; Chaudhary et al., 1996) barring 138.2 days reported recently by Savegnago et al., (2011).

The mature body weight (BW16) was significantly $(\mathrm{P}<0.001)$ high, although the adult and final body weights (BW40 and BW64) were significantly $(\mathrm{P}<0.001)$ low in IWN. Similar trend was reflected in egg weights also with significantly $(\mathrm{P}<0.001)$ higher EW28 and significantly $(\mathrm{P}<0.001)$ lower EW40 and EW64 in IWN compared to IWP. BW16 in the present investigation were higher than that reported by Ahlawat et al., (1982).

Similarly, BW40 observed in this study was higher than those reported by earlier workers in White Leghorn (Chaudhary et al., 1996; Devi and Reddy, 2005). BW64 of both strains was comparatively lower than the 62 weeks body weight reported by Savegnago et al., (2011). Egg weights of similar magnitude have been reported earlier in IWD and IWF strains of White Leghorn at 40 weeks of age by Devi and Reddy (2005). 


\section{Heritability estimates}

Moderate heritability was estimated for EN40 (0.284) and EN64 (0.182) in IWN (Table 3) and IWP (0.239 and 0.220 respectively) (Table 4). This was in conformity with the previously published estimates (Singh and Singh, 2005; Joshi et al., 2005). The heritability values decreased with increasing age in both the strains contrary to the earlier findings (Ferreira et al., 2017). The low magnitude of heritability may be due to the fact that EN being a fitness trait that will express low heritability. Continued selection for egg production during last three decades has resulted in the genetic variation in this trait.

The magnitude of heritability for AFE was high (0.349) in IWN strain compared to IWP (0.09). The heritability estimates for AFE observed in the present study was in agreement with those reported by Ahlawat $e t$ al., (1982), Johari et al., (1988), Sharma et al., (1996) and Singh and Singh (2005) but lower than the report of Savegnago et al., (2011).

The genetic analysis revealed that the body weights at different ages were moderate to highly heritable in IWN strain with a decreasing trend with age $(0.488,0.388$ and 0.284 for BW16, BW40 and BW64 respectively). Similar decreasing trend $(0.318$, 0.285 and 0.242 ) was evident in IWP strain also. This may be due to the fact that the growth traits are well expressed at faster rate of growth, which minimize effects of environmental factors compared to later age. Moderate to high heritability estimated for body weights at various ages obtained in this study were in conformity with the reports of Johari et al., (1988); Sharma et al., (1996) and Singh and Singh (2005) but lower than an estimate of 0.68 for 54 week body weight reported by Savegnago et al., (2011).
The heritability estimates for egg weights at different ages (EW28, EW40 and EW64) ranged from 0.375 to 0.447 in IWN and from 0.460 to 0.505 in IWP strain registering a higher degree of additive genetic action. These results were in agreement with those of Chaudhary et al., (1996), Sharma et al., (1996) and Singh and Singh (2005). The standard errors of all the heritability estimates were of less magnitude implying a reasonably high degree of reliance on these estimates.

\section{Genetic and phenotypic correlations}

A very high positive genetic correlation of 0.824 in IWN (Table 3) and 0.944 in IWP (Table 4) has existed between BW40 and BW64. The positive correlations between egg production of two periods were in conformity with the report of Joshi et al., (2005). A positive genetic correlation of very high magnitude between EN40 and EN64 in IWP reveals a possibility of resorting selection based on 40 week egg production in this strain for attaining maximum genetic improvement per unit time.

In general, the egg production (EN40 and EN64) are negatively associated with AFE on both phenotypic as well as genetic scale. A high degree of negative correlation between EN40 and AFE (-0.832 and -0.835 in IWN and IWP respectively) and EN64 and AFE (0.497 and -0.516) was recorded. The magnitude was fond to be age dependent with strong association in early age (BW40). The magnitude and direction were similar to the findings of Poggenpoel et al., (1996) and Sharma et al., (1996) in White Leghorn.

The correlation between egg number and body weights on both genetic and phenotypic scale from this study was weak and lacked any particular direction. The results clearly revealed that the genetic correlation between EN40 and egg weights (EW28, EW40 and 
EW64) in IWN was in negative direction with values ranging from -0.235 to -0.448 . Similarly genetic correlation between EN64 and egg weights was also in negative direction with similar magnitude $(-0.274$ to 0.455). However, IWP showed low degree of genetic correlation with inconsistent sign between these two traits. The negative genetic correlation between EN and EW in IWN agreed in sign with those reported by several, for example Johari et al., (1988) and Joshi et $a l .(2005)$. The relationship between EW and EN seemed to be near neutral in IWP unlike common rule of strong negative correlation. Therefore the practice of superimposing egg weight as independent culling level in the selection programme can be discarded for some time to get more genetic gain to match the mean of IWN in terms of egg production.

The estimates of genetic and phenotypic correlations between AFE and body weights obtained in this study, were in general, low in magnitude but did not carry any constant sign. Poggenpoel et al., (1996) reported positive genetic correlation of very low magnitude (0.1) between AFE and BW. On the other hand, the estimates from a strain of White Leghorn reported by Narwal et al., (2005) were negative in direction.

The estimates of genetic and phenotypic correlation between AFE and egg weight at different ages (EW28, EW40 and EW64) in IWN were of low to medium degree in negative direction $(-0.109$ to -0.370$)$. In contrast, it was found to be positive with low magnitude (0.005 to 0.232 ) in IWP.

Bodyweights (BW16, BW40 and BW64) among themselves and egg weights among themselves (EW28, EW40 and EW64) showed positive correlation of medium to high magnitude. However the association between body weights and egg weights revealed a general consent of positive association of low to medium magnitude in these two populations. The positive genetic association between and within egg weights and body weights was in conformity with the reports of Poggenpoel et al., (1996), Narwal et al., (2005). It can be concluded that these characters are evidently controlled by both independent and pleiotropic genes.

Table.1 Summary of selection records of parents

\begin{tabular}{|l|l|l|l|}
\hline S1. No. & Particulars & Strains \\
\cline { 3 - 4 } & & IWN & IWP \\
\hline 1 & No. of sires used & 50 & 50 \\
\hline 2 & No. of dams used & 300 & 300 \\
\hline 3 & No. of sires contributed & 50 & 50 \\
\hline 4 & No. of dams contributed & 298 & 296 \\
\hline 5 & Effective number & 171.26 & 171.10 \\
\hline 6 & Rate of inbreeding & 0.002919 & 0.002922 \\
\hline 7 & Expected selection differential for males & 12.252 & 17.335 \\
\hline 8 & Expected selection differential for females & 18.110 & 19.278 \\
\hline 9 & Average selection differential & 15.181 & 18.306 \\
\hline 10 & Effective Selection differential for males & 12.400 & 17.241 \\
\hline 11 & Effective Selection differential for females & 17.823 & 16.794 \\
\hline 12 & Average Effective selection differential & 15.112 & 17.018 \\
\hline 13 & Selection intensity & 0.496 & 0.358 \\
\hline
\end{tabular}


Table.2 Means, standard deviations and minimum and maximum values of different traits

\begin{tabular}{|c|c|c|c|c|c|c|c|c|c|c|c|c|}
\hline \multirow[t]{2}{*}{ Traits (units) } & \multicolumn{6}{|l|}{ IWN } & \multicolumn{6}{|l|}{ IWP } \\
\hline & $\mathrm{n}$ & Mean & SD & $\begin{array}{l}\text { Mini- } \\
\text { mum }\end{array}$ & $\begin{array}{l}\text { Maxi- } \\
\text { mum }\end{array}$ & $\begin{array}{l}\text { Hatch } \\
\text { Effect }\end{array}$ & $\mathrm{n}$ & Mean & SD & $\begin{array}{l}\text { Mini- } \\
\text { mum }\end{array}$ & $\begin{array}{l}\text { Maxi- } \\
\text { mum }\end{array}$ & $\begin{array}{l}\text { Hatch } \\
\text { Effect }\end{array}$ \\
\hline EN40 (no.s) & 2000 & $110.67^{x}$ & 18.37 & 6 & 140 & NS & 2014 & $105.64^{y}$ & 28.37 & 3 & 143 & NS \\
\hline EN64 (no.s) & 2000 & $248.27^{x}$ & 39.39 & 11 & 300 & $*$ & 2014 & $234.46^{y}$ & 59.39 & 9 & 292 & $*$ \\
\hline AFE (days) & 1967 & $154.24^{\mathrm{x}}$ & 10.81 & 131 & 208 & NS & 1967 & $152.65^{y}$ & 12.09 & 130 & 259 & NS \\
\hline BW16 (g) & 2000 & $1064.48^{x}$ & 106.32 & 700 & 1355 & $* *$ & 2014 & $1024.67^{y}$ & 100.59 & 785 & 1350 & $* * *$ \\
\hline BW40 (g) & 1965 & $1560.47^{y}$ & 161.63 & 925 & 2355 & $* * *$ & 1941 & $1587.34^{\mathrm{x}}$ & 165.26 & 960 & 2610 & $* * *$ \\
\hline BW64 (g) & 1919 & $1547.13^{y}$ & 206.46 & 1030 & 2820 & $*$ & 1860 & $1628.28^{x}$ & 222.93 & 1340 & 2780 & $* *$ \\
\hline EW28 (g) & 1919 & $51.12^{x}$ & 2.89 & 40.2 & 62.8 & $* * *$ & 1795 & $50.37^{y}$ & 3.34 & 39.2 & 62.6 & $* * *$ \\
\hline EW40 (g) & 1870 & $54.54^{y}$ & 3.41 & 41.8 & 67.9 & $* * *$ & 1821 & $55.04^{x}$ & 3.89 & 41.8 & 61.3 & $* * *$ \\
\hline EW64 (g) & 1879 & $59.46^{y}$ & 3.83 & 43.4 & 74.7 & $* *$ & 1743 & $60.38^{x}$ & 4.31 & 43.3 & 79.3 & $* * *$ \\
\hline
\end{tabular}

${ }_{\mathrm{x}, \mathrm{y}}$ - Means with different superscripts within a row are significantly $(\mathrm{P} \leq 0.001)$ different; NS - Not significant;* $\mathrm{P} \leq 0.05 ; * * \mathrm{P} \leq 0.01$;

$* * * \mathrm{P} \leq 0.001$

Table.3 Estimates of heritabilities (diagonal), genetic (above the diagonal), and phenotypic (below the diagonal) correlations with their standard errors (in parenthesis) of different traits for IWN strain

\begin{tabular}{|l|l|l|l|l|l|l|l|l|l|}
\hline Traits & EN40 & EN64 & AFE & BW16 & BW40 & BW64 & EW28 & EW40 & EW64 \\
\hline EN40 & 0.284 & 0.824 & -0.832 & 0.219 & -0.054 & 0.033 & -0.388 & -0.448 & $-\mathbf{0 . 2 3 5}$ \\
& $(0.045)$ & $(0.045)$ & $(0.115)$ & $(0.112)$ & $(0.116)$ & $(0.126)$ & $(0.107)$ & $(0.109)$ & $(\mathbf{0 . 1 1 6})$ \\
\hline EN64 & 0.783 & 0.182 & -0.497 & -0.234 & -0.070 & -0.094 & -0.293 & -0.455 & $\mathbf{- 0 . 2 7 4}$ \\
& $(0.01)$ & $(0.037)$ & $(0.141)$ & $(0.125)$ & $(0.132)$ & $(0.140)$ & $(0.122)$ & $(0.120)$ & $(\mathbf{0 . 1 2 6})$ \\
\hline AFE & -0.667 & -0.417 & 0.349 & -0.276 & -0.013 & -0.126 & -0.370 & -0.186 & $-\mathbf{0 . 1 0 9}$ \\
& $(0.02)$ & $(0.020)$ & $(0.048)$ & $(0.109$ & $(0.011)$ & $(0.118)$ & $(0.100)$ & $(0.108)$ & $(\mathbf{0 . 1 1 3})$ \\
\hline BW16 & 0.148 & 0.053 & -0.223 & 0.488 & 0.743 & 0.691 & 0.159 & 0.222 & $\mathbf{0 . 2 0 5}$ \\
& $(0.02)$ & $(0.02)$ & $(0.02)$ & $(0.054)$ & $(0.056)$ & $(0.070)$ & $(0.107)$ & $(0.103)$ & $(\mathbf{0 . 1 0 6})$ \\
\hline BW40 & -0.104 & -0.237 & -0.106 & 0.083 & 0.388 & 0.888 & 0.282 & 0.370 & $\mathbf{0 . 3 8 6}$ \\
& $(0.02)$ & $(0.02)$ & $(0.02)$ & $(0.02)$ & $(0.051)$ & $(0.033)$ & $(0.101)$ & $(0.095)$ & $(\mathbf{0 . 0 9 7})$ \\
\hline BW64 & -0.363 & -0.154 & -0.039 & 0.418 & 0.707 & 0.284 & 0.275 & 0.327 & $\mathbf{0 . 4 4 1}$ \\
& $(0.02)$ & $(0.02)$ & $(0.02)$ & $(0.02)$ & $(0.02)$ & $(0.045)$ & $(0.112)$ & $(0.106)$ & $(\mathbf{0 . 0 9 8})$ \\
\hline EW28 & -0.084 & -0.073 & 0.095 & 0.172 & 0.268 & 0.205 & 0.375 & 0.833 & $\mathbf{0 . 6 6 9}$ \\
& $(0.02)$ & $(0.02)$ & $(0.02)$ & $(0.02)$ & $(0.02)$ & $(0.02)$ & $(0.050)$ & $(0.043)$ & $(\mathbf{0 . 0 6 7})$ \\
\hline EW40 & -0.180 & -0.150 & 0.053 & 0.236 & 0.307 & 0.234 & 0.581 & 0.447 & $\mathbf{0 . 8 6 2}$ \\
& $(0.02)$ & $(0.02)$ & $(0.02)$ & $(0.02)$ & $(0.02)$ & $(0.02)$ & $(0.02)$ & $(0.054)$ & $(\mathbf{0 . 0 3 8})$ \\
\hline EW64 & $\mathbf{- 0 . 0 9 1}$ & $\mathbf{- 0 . 1 1 8}$ & $\mathbf{- 0 . 0 0 4}$ & $\mathbf{0 . 2 0 5}$ & $\mathbf{0 . 2 6 7}$ & $\mathbf{0 . 3 0 5}$ & $\mathbf{0 . 5 0 2}$ & $\mathbf{0 . 6 0 1}$ & $\mathbf{0 . 3 9 0}$ \\
& $(\mathbf{0 . 0 2})$ & $\mathbf{( 0 . 0 2 )}$ & $(\mathbf{0 . 0 2})$ & $(\mathbf{0 . 0 2})$ & $(\mathbf{0 . 0 2})$ & $(\mathbf{0 . 0 2})$ & $(\mathbf{0 . 0 2})$ & $(\mathbf{0 . 0 2})$ & $(\mathbf{0 . 0 5 1})$ \\
\hline
\end{tabular}


Table.4 Estimates of heritabilities (diagonal), genetic (above the diagonal), and phenotypic (below the diagonal) correlations with their standard errors (in parenthesis) of different traits for IWP strain

\begin{tabular}{|l|l|l|l|l|l|l|l|l|l|}
\hline Traits & EN40 & EN64 & AFE & BW16 & BW40 & BW64 & EW28 & EW40 & EW64 \\
\hline EN40 & 0.239 & 0.944 & -0.835 & 0.090 & -0.048 & -0.048 & -0.063 & -0.016 & $\mathbf{0 . 0 7 5}$ \\
& $(0.043)$ & $(0.027)$ & $(0.197)$ & $(0.135)$ & $(0.130)$ & $(0.130)$ & $(0.117)$ & $(0.124)$ & $(\mathbf{0 . 1 2 6})$ \\
\hline EN64 & 0.796 & 0.220 & -0.516 & -0.030 & -0.061 & -0.092 & 0.006 & -0.073 & $\mathbf{0 . 0 0 0}$ \\
& $(0.01)$ & $(0.041)$ & $(0.200)$ & $(0.138)$ & $(0.134)$ & $(0.131)$ & $(0.126)$ & $(0.124)$ & $(\mathbf{0 . 1 2 3})$ \\
\hline AFE & -0.480 & -0.308 & 0.090 & -0.225 & 0.270 & 0.104 & 0.005 & 0.206 & $\mathbf{0 . 2 3 2}$ \\
& $(0.02)$ & $(0.02)$ & $(0.029)$ & $(0.180)$ & $(0.166)$ & $(0.169)$ & $(0.118)$ & $(0.154)$ & $(\mathbf{0 . 1 5 2})$ \\
\hline BW16 & 0.093 & 0.027 & -0.187 & 0.318 & 0.420 & 0.407 & 0.357 & 0.339 & $\mathbf{0 . 3 2 7}$ \\
& $(0.02)$ & $(0.02)$ & $(0.02)$ & $(0.047)$ & $(0.107)$ & $(0.106)$ & $(0.109)$ & $(0.107)$ & $\mathbf{( 0 . 1 0 9})$ \\
\hline BW40 & -0.051 & -0.174 & 0.071 & 0.353 & 0.285 & 0.906 & 0.219 & 0.425 & $\mathbf{0 . 3 7 0}$ \\
& $(0.02)$ & $(0.02)$ & $(0.02)$ & $(0.02)$ & $(0.045)$ & $(0.034)$ & $(0.110)$ & $(0.096)$ & $(\mathbf{0 . 1 0 3})$ \\
\hline BW64 & -0.051 & -0.091 & 0.002 & 0.336 & 0.701 & 0.242 & 0.063 & 0.258 & $\mathbf{0 . 2 4 4}$ \\
& $(0.02)$ & $(0.02)$ & $(0.02)$ & $(0.02)$ & $(0.02)$ & $(0.043)$ & $(0.116)$ & $(0.108)$ & $(\mathbf{0 . 1 0 6})$ \\
\hline EW28 & 0.029 & 0.013 & 0.015 & 0.136 & 0.140 & 0.092 & 0.460 & 0.892 & $\mathbf{0 . 8 7 5}$ \\
& $(0.02)$ & $(0.02)$ & $(0.02)$ & $(0.02)$ & $(0.02)$ & $(0.02)$ & $(0.056)$ & $(0.036)$ & $(\mathbf{0 . 0 3 8})$ \\
\hline EW40 & -0.071 & -0.053 & 0.053 & 0.108 & 0.135 & 0.096 & 0.548 & 0.491 & $\mathbf{0 . 9 4 0}$ \\
& $(0.02)$ & $(0.02)$ & $(0.02)$ & $(0.02)$ & $(0.02)$ & $(0.02)$ & $(0.02)$ & $(0.057)$ & $(\mathbf{0 . 0 2 6})$ \\
\hline EW64 & $\mathbf{0 . 0 1 7}$ & $\mathbf{0 . 0 1 0}$ & $\mathbf{0 . 0 3 2}$ & $\mathbf{0 . 0 8 6}$ & $\mathbf{0 . 1 2 0}$ & $\mathbf{0 . 1 3 5}$ & $\mathbf{0 . 5 4 5}$ & $\mathbf{0 . 5 9 8}$ & $\mathbf{0 . 5 0 5}$ \\
& $(\mathbf{0 . 0 2})$ & $(\mathbf{0 . 0 2})$ & $(\mathbf{0 . 0 2})$ & $\mathbf{( 0 . 0 2})$ & $\mathbf{( 0 . 0 2})$ & $(\mathbf{0 . 0 2})$ & $(\mathbf{0 . 0 2})$ & $(\mathbf{0 . 0 2})$ & $(\mathbf{0 . 0 5 8})$ \\
\hline
\end{tabular}

Table.5 Response to selection in primary and associated traits

\begin{tabular}{|l|l|l|l|l|}
\hline \multirow{2}{*}{ Traits } & \multicolumn{2}{l|}{$\begin{array}{l}\text { Phenotypic } \\
\text { response }\end{array}$} & \multicolumn{2}{l|}{ Genetic response } \\
\cline { 2 - 5 } & IWN & IWP & IWN & IWP \\
\hline BW16 & -57.7 & -111 & 31.53 & -21.76 \\
\hline BW40 & -57.8 & -102 & 56.7 & 12.94 \\
\hline BW64 & -26.10 & -22.76 & 179.64 & 182.98 \\
\hline ASM & 15.99 & 17.03 & 12.89 & 13.93 \\
\hline EW28 & 0.87 & 0.07 & 0.9 & 0.1 \\
\hline EW40 & 1.11 & 1.57 & 0.92 & 1.38 \\
\hline EW64 & 4.91 & 6.73 & 2.5 & 4.32 \\
\hline $\begin{array}{l}\text { EN40(Hen } \\
\text { housed) }\end{array}$ & -7.2 & -8.15 & -8.79 & -9.74 \\
\hline $\begin{array}{l}\text { EN64(Hen } \\
\text { housed) }\end{array}$ & 3.38 & 3.47 & -0.38 & -0.29 \\
\hline
\end{tabular}


Fig.1 Frequency distribution of egg production upto 64 weeks of age
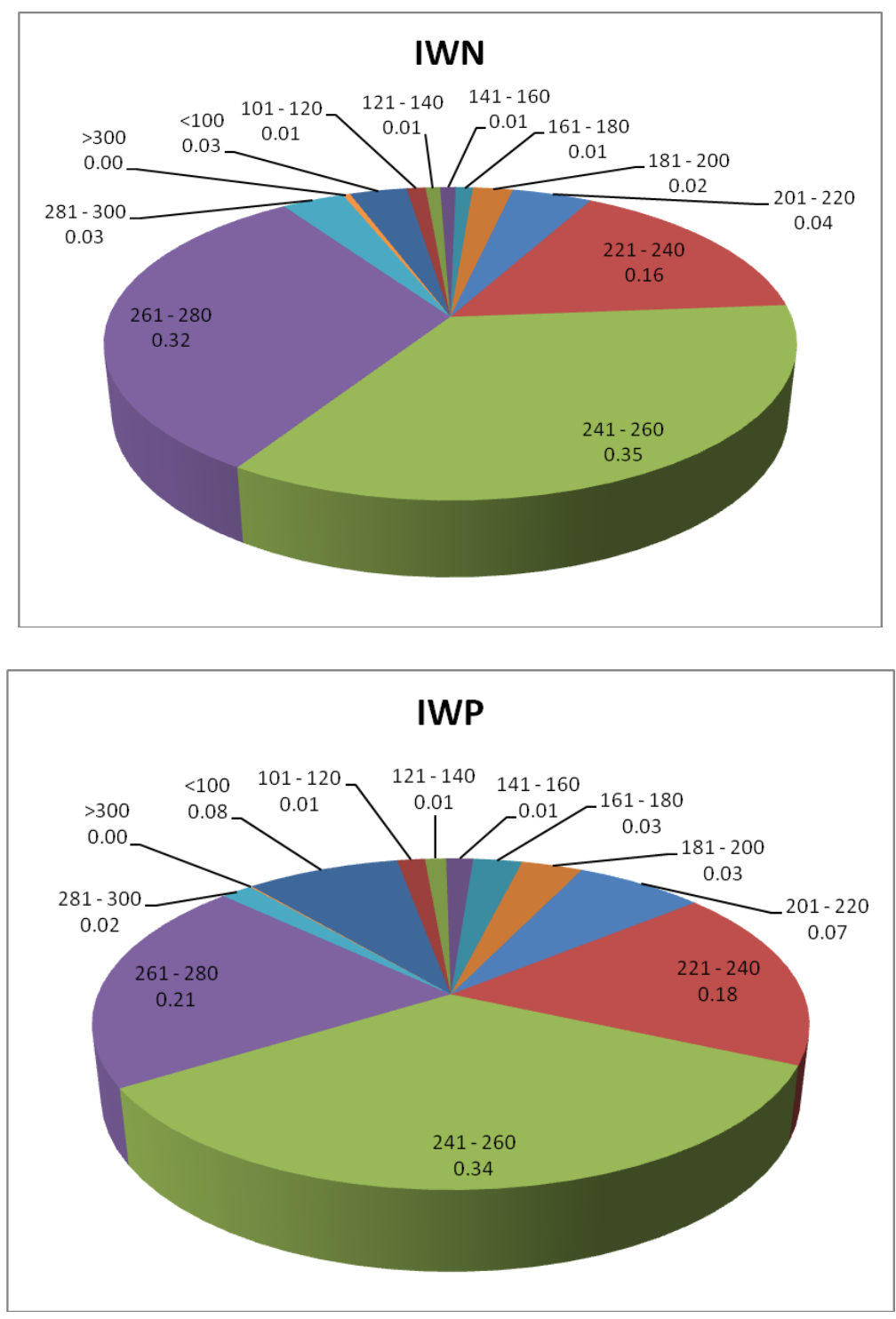

\section{Response to selection}

The EN64 (hen housed) registered an improvement of 3.38 and 3.47 eggs in IWN and IWP respectively on phenotypic scale (Table 5). However, the response was slightly on negative side on genetic scale. Egg weight, another important economic trait in general had a positive shift on both phenotypic and genetic scale. Other traits however had inconsistent trends. Venkatramaiah et al., (1986) have reported a genetic response of 2.16 eggs per generation in White Leghorn.
The heritability estimates for egg production in both the populations revealed that substantial amount of genetic variation can exist in White Leghorn even after very long term selection experiments for full record egg production (EN64). It may also be concluded that genetic correlation between EN40 and EN64 in IWN strain was such that selection for EN40 would allow improvement in EN64 without seriously compromising the selection objective of the breeding programme. The genetic properties of IWP reveal the possibility for discontinuation of 
superimposing egg weight as independent culling level in breeding programme for augmenting genetic gain in egg number which is a low producing strain. Examination of the genetic properties of two populations, IWP strain by virtue of early sexual maturity and higher egg weights can serve well as male line and IWN as dam line for producing hybrid crosses.

\section{References}

Ahlawat, S. P. S., Chaudhary, R.P. and Singh, B. P. (1982).Estimates of genetic parameters for high egg number in a combined selection programme of white Leghorn. Indian Vet. J., 59: 799-805.

Chaudhary, M. L., Brah, G. S. and Sandhu, J. S., (1996). Genetic inferences from comparison of pure- and cross-line White Leghorns. Indian J. Poult. Sc., 32: 28-32.

Cole, R. F. and Hutt, F. B. (1973). Selection and heterosis in Cornell White Leghorn: A review with special consideration of inter strain hybrids. Animal Breeding Abstracts, 41: 10318.

Devi K S and Reddy P M. (2005). Genetic studies on certain economic traits in White Leghorn and cross-bred chicken. Indian J. Poult. Sci., 40: 5658.

Dryden, J. (1921). Egg-laying characteristics of the hen. Oregon Agric. Exp. Sta. Bull., 180.

Fairfull, R. W. and Gowe, R. S. (1990). Genetics of egg production. In: Poultry Breeding and Genetics. Elsevier, Amsterdam, pp 705-759.

Falconer, D. S. (1989). Introduction to Quantitative Genetics, $3^{\text {rd }}$ Ed., Longman Group, UK Ltd., London.

Ferreira, P. B., Rorato, P. R. N., Breda, F. C., Michelotti, V. T., Rosa, Alexandre P. and Macedo, A. (2017). Genotypic parameters for egg production in pure breed hens by using random regression model. Ciência Rural., 47: $1-7$.

Harvey, W. R. (1966). Least square analysis of data with unequal subclass number. USDA, ARS; 20:8.

Johari, D. C., Dey, B. R., Kataria, M. C., Ayyagari, V., Mohapatra, S. C. and Gopal, R. (1988). Genetic variation and covariation of production traits in White Leghorn selected for part record egg production. Indian J. Poult. Sci., 23:40-46.

Joshi, R. S., Barot, V. N., Patel, A. B., Savalia, F. P., Mishra, R. K., Paleja, H. I. and Khanna, K. (2005). A genetic study on egg production traits in two strains of white Leghorn. Proceedings of XXIII conference of Indian Poultry Science Association (IPSACON) - Vol.II., Hyderabad, India.

Narwal, S., Malik, C. P., Raheja, K. L. and Kalra, S. (2005). Genetic studies on performance traits of egg type chickens. Proceedings of XXIII conference of Indian Poultry Science Association (IPSACON) - Vol. II., Hyderabad, India.

Nordskog, A. W. and Briggs, D. M. (1968). The body weight egg production paradox. Poult. Sci., 47:498-504.

Osborne, R. (1957a). The use of sire and dam family averages in increasing the efficiency of selective breeding under a hierarchical mating system. Heredity, 11: 93-116.

Osborne, R. (1957b). Family selection in poultry. The use of sire and dam family averages in choosing male parents. Proceedings of Royal Society, Edinburgh, 66: 374-393.

Poggenpoel, D. G., Ferreira, G. F., Hayes, J. P. and duPreez, J.J. (1996). Response 
to long-term selection for egg production in laying hens. Br. Poult. Sci., 37: 743-756.

Savegnago, R. P., Caetano, S. L., Ramos, S. B., Nasciment, G. B., Schmidt, G. S., Ledur, M. C. and Munari, D. P. (2011). Estimates of genetic parameters, and cluster and principal components analyses of breeding values related to egg production traits in a White Leghorn population, Poult. Sci., 90: 2174-2188.

Sharma, D., Johari, D. C., Kataria, M. C., Singh, B. P., Singh, D. P. and Hazary, R. C. (1996). Effect of long term selection on genetic parameters of economic traits in White Leghorn. Asian-Australas J. Anim. Sci.,9: 455459.
Singh, N. and Singh, R. P. (2005). Heritability estimates of performance traits in purebred and crossbred egg type chicken. Indian J. Poult. Sci., 40: 5255.

Singh, R., Cheng, K. M. and Silversides, F. G. (2009). Production performance and egg quality of four strains of laying hens kept in conventional cages and floor pens. Poult. Sci., 88: 256-264.

Snedecor, G. W. and Cochran, W. G. (1989). Statistical Methods, Eighth Edition, Iowa State University Press.

Venkatramaiah, A., Mohapatra, S. C., Sinha, R., Ayyagari, V. and Chaudhuri, D. (1986). Selection response for part period egg number and egg mass in chicks - a comparison. Theor.Appl. Genet., 72: 129 - 134.

\section{How to cite this article:}

Churchil, R.R., Lijo John, Binoj Chacko, P. Ezhil Praveena and Anitha, P. 2019. Genetic Analysis of Egg Production and Allied Characters in Two Long Term Selected Strains of White Leghorn. Int.J.Curr.Microbiol.App.Sci. 8(03): 1669-1678.

doi: https://doi.org/10.20546/ijcmas.2019.803.194 